\title{
THE WORK-OUTS TO OPTIMIZE THE EFFICIENCY FOOTWORK - A CASE STUDY FOR TALENTED FEMALE TABLE TENNIS ATHLETES AT THE AGE OF 14-15 IN VINH LONG PROVINCE, VIETNAM
}

\author{
Tuan, Tran Minh ${ }^{1 i}$; \\ Dinh, Nguyen $\mathrm{Mai}^{2}$ \\ ${ }^{\text {Saigon University, }}$ \\ Vietnam \\ ${ }^{2}$ Cao Thang Technical College, \\ Vietnam
}

\begin{abstract}
:
The purpose of this study was to build up and evaluate the application of work-outs about the efficiency of footwork for talented female table tennis athletes. 08 healthy female talented table tennis athletes at the age of 14-15 in Vinh Long province were chosen to participate in the 8-week pre-season training. Results indicated that the 20 work-outs were selected to improve the efficiency footwork through the basis of training principle, participant' characteristics, previous studies, and expert interviews. Besides, there were significant differences in all 06 tests to evaluate the footwork ability after the experiment. Moreover, the percentage of change indicated increased, from the objective perspective, we found that the growth rate was still at the moderate level (from $2.72 \%$ to $6.07 \%$ ). Therefore, it is necessary to apply the 20 work-outs more flexibly and closely to improve the efficiency of footwork in different training phases next year. It was concluded that the application of the 20 work-outs about the efficiency of footwork had positive effects on female talented table tennis athletes. Future studies should be conducted on a group of males, diverse in training levels, and/or on the other sports group that need to promote footwork ability.
\end{abstract}

Keywords: efficiency footwook, the 20 work-outs, female talented athletes, aged 14-15, table tennis

\section{Introduction}

Speed, reaction time, and technical skills were the basic features in table tennis to meet the nature of the Game, e.g. fast pace, quick response, and flexibility in any circumstances

\footnotetext{
i Correspondence: email tmtuan@sgu.edu.vn
} 
(Kondrič et al., 2013; Ripoll et al., 1987). Besides, high concentration of attention and stable psychological stability were important points to becoming a good table tennis athlete (Kahn et al., 2004; Yuza et al., 1992; Zhang et al., 2012). Through the practical investigation results of training and the experience in the competition, training time might be more than 7 hours per day in elite athletes and over 4 hours in young athletes. While the average time in table tennis competition was 18-48 minutes (15-34 minutes for Vietnamese athletes), not counting the time for a break or picking up the ball (Mason, 1986). Moreover, the total number of swings to hit the ball was from 302-1246 times (3001200 for Vietnamese athletes), along with table tennis athletes had to move continuously and rapidly during the competition from 100-250 times, equivalent to the distance for running was $1000-3000 \mathrm{~m}$. Thus, the density of movement was quite high, from $0.26-0.69$ times in one second (Mao, 2012). In addition, table tennis athletes had to perform with the optimum precision to effectively catch/hit the ball (Muelling et al., 2014) and moved quickly and continuously in competition (Toriola et al., 2004). In order to meet these criteria in table tennis, athletes have to pay special attention to the combination of leg flexibility in each specific situation, also called footwork (Son \& Vinh, 2020). This will help athletes move to a favorable position and perform the return better and more accurately (Welford, 1980). Therefore, it is necessary to build up the work-outs to improve the efficiency of footwork, which maximized the inherent talent of young table tennis players and enhanced the achievements and skills in competition.

\section{Materials and Methods}

\subsection{Participants}

The volunteer and selected participants were 08 healthy female talented table tennis athletes at the age 14-15 in Vinh Long province, Vietnam. None of the participants had any physical problems, smoking, alcohol using or were taking any medication. All of the participants took part in the pre-season training in 8 weeks with the application of the 20 work-outs (more details in Table 1). They were informed of the test procedures before providing written consent. This study was approved by Vinh Long province, head coach, and the Provincial Scientific Council for the use of human beings.

\subsection{Procedures}

Two weeks before, each participant answered a brief baseline questionnaire about their personal information and sport-related injury history (excluded if any problem occurred). One week after that, all participants came to examine their footwork ability (pre-test) before the pre-season training program began. 06 tests were used to evaluate the efficiency of footwork such as $60 \mathrm{~m}$ sprint (s), $8 \times 8 \mathrm{~m}$ shuttle run (s), pick up 21 balls in $3 \mathrm{~m}(\mathrm{~s})$, a combination of moving left and right to return the ball in 1 minute (times), move $2 / 3$ horizontally to hit the ball in 1 minute (times), and 2-minute rope jumping (times). These tests had high validity and reliability for determining the footwork efficiency in young table tennis athletes (Son \& Vinh, 2020). 
Table 1: The application of the 20-work-out for female talented table tennis athletes

\begin{tabular}{|c|c|c|c|c|c|c|c|c|c|c|c|c|c|c|c|c|c|c|c|c|c|c|c|c|c|c|c|c|c|}
\hline & \multicolumn{10}{|c|}{ T } \\
\hline
\end{tabular}

Notes: T: the 20-footwork work-outs, 1: Change of direction when given signal, 2: Change of direction with weights on legs to simulate the return when given the signal in 45 seconds, 3: 30m sprint, 4: 60m sprint, 5: $8 \times 8 \mathrm{~m}$ shuttle run, 6: Forehand and backhand with weights on legs in 45 seconds, 7 : Holding the iron racket and moving side by side to simulate the hit 30 seconds, 8: Move horizontally $3 \mathrm{~m}$ to pick up 30 balls, 9: Left and right moving to return the ball in 3 minutes, 10: Backward and forward moving to return the ball in 3 minutes, 11: Left push and right loop in 5 minutes, 12: Left and right moving to smash the ball in 5 minutes, 13: Move 2/3 horizontally to hit the ball in 5 minute, 14: Loop left corner in 3 minutes, 15: Short right smash and move to left push in 4 minutes, 16: Right loop and move to short left smash in 4 minutes, 17: Left and right moving to loop the ball in 3 minutes, 18: Simulation the smash when given signal in 1 minute, 19: Rope jumping in 1 minute, 20: Trial competitions (3-5 games).

Based on the yearly training program of the table tennis players in Vinh Long province and the annual competition schedule (e.g. the Tien Phong Newspaper championships in July, the Youth National table tennis championships (the 12-outstanding-player prize) in August, and Phu Dong Festival in September), should be completed by July. All participants would experience 8-week pre-season training, six times per week (except Sunday), three hours training each day, in which 60 minutes for footwork training. The time for training was 8.00 to 11.00 am. However, on Tuesday and Thursday, participants had the weight training, so that the application of the 25-work-out for female talented table tennis athletes was conducted four days/week (Monday, Wednesday, Friday, and Saturday). The total time of the 8-week pre-season training plan is presented in Table 2. 
Table 2: Percentage of practical time in the 8-week pre-season training

\begin{tabular}{|l|c|c|c|c|c|}
\hline Types of training & $\mathbf{\%}$ & Total time & Training phases & $\mathbf{\%}$ & Practical times \\
\hline \multirow{2}{*}{ Physical fitness } & \multirow{2}{*}{$65 \%$} & \multirow{2}{*}{52 hours } & General fitness & $80 \%$ & 42 hours \\
\cline { 4 - 6 } & & Specific training & $20 \%$ & 10 hours \\
\hline \multirow{2}{*}{ Skills and tactics } & \multirow{2}{*}{$35 \%$} & \multirow{2}{*}{28 hours } & Skills training & $97 \%$ & 26 hours \\
\cline { 4 - 6 } & & Tactics training & $7 \%$ & 2 hours \\
\hline Summary & $\mathbf{1 0 0} \%$ & $\mathbf{8 0}$ hours & & $\mathbf{1 0 0} \%$ & $\mathbf{8 0}$ hours \\
\hline
\end{tabular}

At the end of the 8-week, all participants underwent the examination as in pre-test (also called the post-test).

\subsection{Statistical analysis}

All data are expressed as mean and standard deviation values (mean \pm SD). Data collections were analyzed by using Microsoft Excel for Windows and the SPSS for Windows version 20. Descriptive analysis was used to describe the subject characteristics. Pair Sample T-test was used to determine the differences between pre-test and post-test. The level of statistical significance was set at $\mathrm{p}<.05$.

\section{Results and Discussions}

Participants' characteristics were shown in Table 3.

Table 3: Participants' characteristics

\begin{tabular}{|c|c|c|c|}
\hline $\mathbf{n = 8}$ & Age (year) & Weight $\mathbf{( k g )}$ & Height $\mathbf{( c m )}$ \\
\hline Mean \pm SD & $14.25 \pm 0.46$ & $43.93 \pm 1.31$ & $155.88 \pm 4.02$ \\
\hline
\end{tabular}

The average age, height, and weight of 08 female talented table tennis athletes in Vinh Long province were $14.25 \pm 0.46$ years, $155.88 \pm 4.02 \mathrm{~cm}$, and $43.93 \pm 1.31 \mathrm{~kg}$, respectively. Besides, following these three steps, authors built up the work-out to improve footwork in table tennis for female talented table tennis athletes.

Step 1: The basis of the work-outs selection. Based on the training principles to choose as the work-out had to be oriented to develop physical fitness, could be suited to the characteristic of participants, met the practical conditions of female athletes, be effective to enhance the efficiency of footwork, created the excitement and diversity.

Step 2: Systematization of the work-outs from previous studies. From the basis in step 1 and results from many previous studies (Amelin, 1985; Cang, 2002; Kondrič et al., 2013; Mason, 1986; Quang \& Thai, 1995; Seemiller \& Holowchak, 1997; Thai \& Son, 1999; Yuza et al., 1992) we initially synthesized and selected 25 work-outs to improve footwork as following: (1) Change of direction when given signal, (2) Change of direction with weights on legs to simulate the return when given the signal in 45 seconds, (3) 30m sprint, (4) 60m sprint, (5) 30 times jump and switch legs side by side, (6) 8x8m shuttle run, (7) Forehand and backhand with weights on legs in 45 seconds, (8) Holding the iron racket and moving side by side to simulate the hit 30 seconds, (9) Move horizontally $4 \mathrm{~m}$ to pick 
up 42 balls, (10) Move horizontally $3 \mathrm{~m}$ to pick up 30 balls, (11) Left and right moving to return the ball in 3 minutes, (12) Backward and forward moving to return the ball in 3 minutes, (13) Left push and right loop in 5 minutes, (14) Left and right moving to smash the ball in 5 minutes, (15) Move 2/3 horizontally to hit the ball in 5 minute, (16) Loop left corner in 3 minutes, (17) Short right smash and move to left push in 4 minutes, (18) Right loop and move to short left smash in 4 minutes, (19) Short left serve and move right loop to the corner in 4 minutes, (20) Left and right moving to loop the ball in 3 minutes, (21) Simulation the smash when given signal in 1 minute, (22) Rope jumping in 1 minute, (23) Trial competitions (3-5 games), (24) Lift the ball with racket in 5m, (25) 3m cross-step running.

Step 3: Expert interview. 15 experts (included coaches, trainers, managers who had at least five years of training in table tennis) were chosen to evaluate the feasibility of the 25 work-outs from step 2. The questionnaire was sent two times, three months apart, to the same expert. A 3-level rating was used (e.g. Used - Rarely - No used) and coded to $0-1-2$ points respectively. Thus, the fewer points respondent had, the fewer the work-outs used. After summarizing the results, the selected would be converted into points. Results of the expert interviews are presented in Table 2.

Table 2: Results from the expert interviews

\begin{tabular}{|c|c|c|c|c|c|c|c|c|c|c|}
\hline \multirow{3}{*}{$\begin{array}{l}\text { Work- } \\
\text { outs }\end{array}$} & \multicolumn{5}{|c|}{ First time $(n=15)$} & \multicolumn{5}{|c|}{ Second time $(n=15)$} \\
\hline & \multicolumn{3}{|c|}{ Evaluation (points) } & \multirow{2}{*}{$\begin{array}{l}\text { Total } \\
\text { point }\end{array}$} & \multirow{2}{*}{$\begin{array}{c}\% \\
\text { Used }\end{array}$} & \multicolumn{3}{|c|}{ Evaluation (points) } & \multirow{2}{*}{$\begin{array}{l}\text { Total } \\
\text { point }\end{array}$} & \multirow{2}{*}{$\begin{array}{c}\% \\
\text { Used }\end{array}$} \\
\hline & Used & Rarely & No & & & Used & Rarely & No & & \\
\hline 1 & 12 & 2 & 1 & 26 & 86.67 & 12 & 2 & 1 & 26 & 86.67 \\
\hline 2 & 11 & 3 & 1 & 25 & 83.33 & 11 & 3 & 1 & 25 & 83.33 \\
\hline 3 & 13 & 2 & 0 & 28 & 93.3 & 13 & 2 & 0 & 28 & 93.3 \\
\hline 4 & 11 & 2 & 2 & 25 & 83.33 & 11 & 3 & 1 & 25 & 83.33 \\
\hline 5 & 9 & 4 & 2 & 22 & 73.33 & 9 & 4 & 2 & 22 & 73.33 \\
\hline 6 & 15 & 0 & 0 & 30 & 100 & 14 & 1 & 0 & 29 & 96.7 \\
\hline 7 & 13 & 1 & 1 & 27 & 90 & 13 & 1 & 1 & 27 & 90 \\
\hline 8 & 14 & 1 & 0 & 29 & 96.7 & 13 & 2 & 0 & 28 & 93.3 \\
\hline 9 & 8 & 5 & 2 & 21 & 70 & 8 & 4 & 3 & 20 & 66.7 \\
\hline 10 & 12 & 2 & 1 & 26 & 86.67 & 12 & 2 & 1 & 26 & 86.67 \\
\hline 11 & 14 & 1 & 0 & 29 & 96.7 & 13 & 2 & 0 & 28 & 93.3 \\
\hline 12 & 13 & 2 & 0 & 28 & 93.3 & 12 & 2 & 1 & 26 & 86.67 \\
\hline 13 & 12 & 3 & 0 & 27 & 90 & 12 & 3 & 0 & 27 & 90 \\
\hline 14 & 11 & 3 & 1 & 25 & 83.33 & 11 & 3 & 1 & 25 & 83.33 \\
\hline 15 & 11 & 3 & 1 & 25 & 83.33 & 11 & 3 & 1 & 25 & 83.33 \\
\hline 16 & 15 & 0 & 0 & 30 & 100 & 15 & 0 & 0 & 30 & 100 \\
\hline 17 & 14 & 1 & 0 & 29 & 96.7 & 13 & 2 & 0 & 28 & 93.3 \\
\hline 18 & 11 & 3 & 1 & 25 & 83.33 & 11 & 3 & 1 & 25 & 83.33 \\
\hline 19 & 8 & 4 & 3 & 20 & 66.67 & 8 & 4 & 3 & 20 & 66.67 \\
\hline 20 & 14 & 1 & 0 & 29 & 96.7 & 13 & 2 & 0 & 28 & 93.3 \\
\hline 21 & 11 & 3 & 1 & 25 & 83.33 & 11 & 3 & 1 & 25 & 83.33 \\
\hline 22 & 12 & 3 & 0 & 27 & 90 & 12 & 3 & 0 & 27 & 90 \\
\hline 23 & 15 & 0 & 0 & 30 & 100 & 15 & 0 & 0 & 30 & 100 \\
\hline
\end{tabular}




\begin{tabular}{|l|l|l|l|l|l|l|l|l|l|l|}
\hline \hline 24 & 9 & 4 & 2 & 22 & 73.33 & 9 & 5 & 1 & 23 & 76.7 \\
\hline 25 & 9 & 5 & 1 & 23 & 76.67 & 9 & 3 & 3 & 21 & 70 \\
\hline
\end{tabular}

Notes: 1: Change of direction when given signal, 2: Change of direction with weights on legs to simulate the return when given the signal in 45 seconds, 3: 30m sprint, 4: 60m sprint, 5: 30 times jump and switch legs side by side, 6: 8x8m shuttle run, 7: Forehand and backhand with weights on legs in 45 seconds, 8 : Holding the iron racket and moving side by side to simulate the hit 30 seconds, 9: Move horizontally $4 \mathrm{~m}$ to pick up 42 balls, 10: Move horizontally $3 \mathrm{~m}$ to pick up 30 balls, 11: Left and right moving to return the ball in 3 minutes, 12: Backward and forward moving to return the ball in 3 minutes, 13: Left push and right loop in 5 minutes, 14: Left and right moving to smash the ball in 5 minutes, 15: Move 2/3 horizontally to hit the ball in 5 minute, 16: Loop left corner in 3 minutes, 17: Short right smash and move to left push in 4 minutes, 18: Right loop and move to short left smash in 4 minutes, 19: Short left serve and move right loop to the corner in 4 minutes, 20: Left and right moving to loop the ball in 3 minutes, 21: Simulation the smash when given signal in 1 minute, 22: Rope jumping in 1 minute, 23: Trial competitions (3-5 games), 24: Lift the ball with racket in 5m, 25: $3 \mathrm{~m}$ cross-step running.

From the results of expert interviews in Table 2, we selected the work-outs with a total point of more than 25 (or higher than $80 \%$ ). According to this principle, the 20 -work-out was chosen such as (1) change of direction when given signal, (2) change of direction with weights on legs to simulate the return when given the signal in 45 seconds, (3) 30m sprint, (4) 60m sprint, (5) 8x8m shuttle run, (6) forehand and backhand with weights on legs in 45 seconds, (7) Holding the iron racket and moving side by side to simulate the hit 30 seconds, (8) move horizontally $3 \mathrm{~m}$ to pick up 30 balls, (9) left and right moving to return the ball in 3 minutes, (10) backward and forward moving to return the ball in 3 minutes, (11) left push and right loop in 5 minutes, (12) left and right moving to smash the ball in 5 minutes, (13) move 2/3 horizontally to hit the ball in 5 minute, (14) loop left corner in 3 minutes, (15) short right smash and move to left push in 4 minutes, (16) right loop and move to short left smash in 4 minutes, (17) left and right moving to loop the ball in 3 minutes, (18) simulation the smash when given signal in 1 minute, (19) rope jumping in 1 minute, (20) trial competitions (3-5 games). Therefore, through the three steps above, the authors have selected the 20-work-out to improve the efficiency of footwork for female talented table tennis athletes at the age of 14-15 years.

Moreover, results of the effectiveness of the application of the 20-work-outs in footwork for female talented table tennis athletes aged 14-15 are presented in Table 3.

Table 3: Differences in the efficiency footwork between before and after the experiment

\begin{tabular}{|c|c|c|c|c|}
\hline Test & Before experiment (pre-test) & After experiment (post-test) & GR (\%) & t \\
\hline 1 & $10.24 \pm 0.65$ & $9.72 \pm 0.4$ & 5.16 & $3.757^{*}$ \\
\hline 2 & $20.51 \pm 0.93$ & $19.96 \pm 0.97$ & 2.72 & $7.044^{*}$ \\
\hline 3 & $62.00 \pm 0.91$ & $58.35 \pm 0.8$ & 6.07 & $8.632^{* *}$ \\
\hline 4 & $61.38 \pm 2.34$ & $63.50 \pm 1.1$ & 3.40 & $2.861^{*}$ \\
\hline 5 & $61.75 \pm 2.44$ & $64.13 \pm 1.54$ & 3.77 & $3.493^{*}$ \\
\hline 6 & $308.88 \pm 6.27$ & $321.75 \pm 1.98$ & 4.08 & $6.424^{*}$ \\
\hline
\end{tabular}

Notes: 1: 60m sprint (s), 2: 8x8m shuttle run (s), 3: pick up 21 balls in 3m (s), 4: combination of moving left and right to return the ball in 1 minute (times), 5: move $2 / 3$ horizontally to hit the ball in 1 minute (times), 6: 2-minute rope jumping (times). GR: Growth Rate (\%). ${ }^{*}{ }^{* *}$ significant differences at the level 0.05, 0.01 . 
Results in Table 3 showed that there were statistically significant differences in all evaluation tests to improve the efficiency of footwork for female talented table tennis athletes at the age of 14-15. It means that the application of 20-work-outs in this study has a positive effect on participants, which enhanced their footwork ability in training. According to Raab et al. (2005) indicated that most previous studies focused on technical and tactics enhancement. It meant that we missed out on many other aspects of sports success as what kinds of movement the athletes perform and how it can be done, especially in young athletes (Cang, 2002; Muelling et al., 2014). In our study, we built up the work-outs to improve the efficiency of footwork - one of the aspects to make table tennis athletes move to a convenient and suitable position to have many options to deal with the opponent's return situations.

In addition, results in this study also showed that there was growth in all evaluation tests, but the growth rate was still quite modest, from $2.72 \%-6.07 \%$ (shown in Figure 1).

Therefore, for better development of efficient footwork, these work-outs should be applied during the following year's training cycle to enhance the achievement performance for athletes. Future studies should be conducted on a group of males, diverse in training levels, and/ or on the other sports group that need to promote footwork ability.

\section{Conclusions}

In short, the study has identified the 20 work-outs to improve the footwork efficiency and applied these work-outs to the 8-week pre-season training for female talented table tennis athletes. The application of these work-outs has brought a positive effect and is suitable for the development of footwork in female athletes at the age of 14-15 in Vinh Long province, Vietnam.

Figure 1: The growth rate of all tests for evaluating the efficiency footwork

\section{Growth rate (\%)}

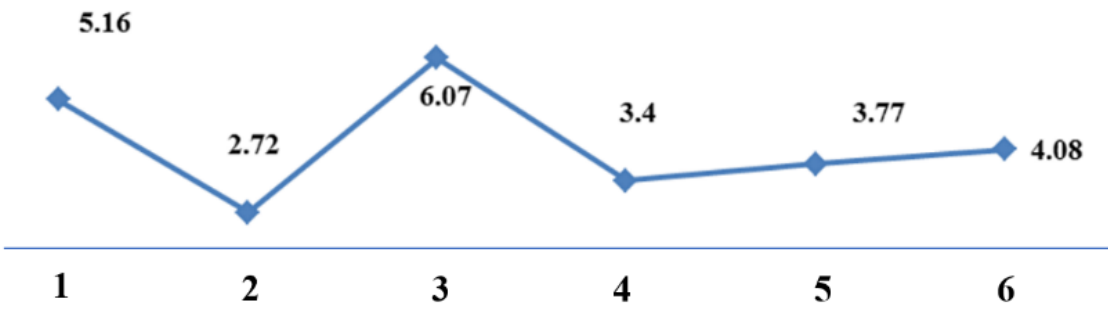

Notes: 1: 60m sprint (s), 2: 8x8m shuttle run (s), 3: pick up 21 balls in $3 \mathrm{~m}$ (s), 4: combination of moving left and right to return the ball in 1 minute (times), 5: move $2 / 3$ horizontally to hit the ball in 1 minute (times), 6: 2-minute rope jumping (times). 


\section{Authors' contributions}

Tuan, Tran Minh (Corresponding author) drafted, wrote down, and revised the manuscript while the other author Dinh, Nguyen Mai took a control in revising and editing the manuscript after all. Both authors have approved the latest paper of this manuscript. We both agreed with the order of the presentation.

\section{Competing interests}

Both authors declare that they have no competing interests.

\section{About the authors}

Dr. Tuan, Tran Minh works as an energetic and determined specialist in Sports science, coaching and Physical Education at Saigon University, Vietnam.

M. E. Dinh, Nguyen Mai works as a coach in table tennis and lecturer at Cao Thang Technical College, Vietnam.

\section{References}

Amelin, A. N. (1985). Modern table tennis. Sports Publishing.

Cang, L. T. (2002). Research and application of some exercises to develop physical fitness in the process of training male table tennis players 13-14 years old Hochiminh City University of Sports ]. Ha Noi, Vietnam.

Kahn, J. F., Lees, A., \& Maynard, I. (2004). Science and Racket Sports III: The Proceedings of the Eighth International Table Tennis Federation Sports Science Congress and The Third World Congress of Science and Racket Sports. Taylor \& Francis. https://books.google.com.vn/books?id=z9t-AgAAQBAI

Kondrič, M., Zagatto, A. M., \& Sekulić, D. (2013). The physiological demands of table tennis: a review. Journal of sports science $\mathcal{E}$ medicine, 12(3), 362-370. https://pubmed.ncbi.nlm.nih.gov/24149139 https://www.ncbi.nlm.nih.gov/pmc/articles/PMC3772576/

Mao, B. J. (2012). Different Techniques Comparison in Biomechanical Analysis of Ping Pong. Applied Mechanics and Materials, 166-169, 3106-3109. https://doi.org/10.4028/www.scientific.net/AMM.166-169.3106

Mason, B. (1986). The possible use of biomechanical analysis for the identification of talent in table tennis. Excel, 2(4), 6-8.

Muelling, K., Boularias, A., Mohler, B., Schölkopf, B., \& Peters, J. (2014). Learning strategies in table tennis using inverse reinforcement learning. Biological Cybernetics, 108(5), 603-619. https://doi.org/10.1007/s00422-014-0599-1

Quang, B. H., \& Thai, N. D. (1995). The application of tests to evaluate the physical fitness for young table tennis athletes. Science and Technical in Sports, 5(6). 
Raab, M., Masters, R. S. W., \& Maxwell, J. P. (2005). Improving the 'how' and 'what' decisions of elite table tennis players. Human Movement Science, 24(3), 326-344. https://doi.org/10.1016/j.humov.2005.06.004

Ripoll, H., Fleurance, P. H., \& Cazeneuve, D. (1987). Analysis of Visual Patterns Ok Table Tennis Players. In J. K. O'Regan \& A. Levy-Schoen (Eds.), Eye Movements from Physiology to Cognition (pp. 616-617). Elsevier. https://doi.org/10.1016/B978-0-444$\underline{70113-8.50085-0}$

Seemiller, D., \& Holowchak, M. (1997). Winning table tennis. Human Kinetics.

Son, N. Q., \& Vinh, N. Q. (2020). Research of physical fitness tests in the selection of 8-9 year old females table tennis players in Ho Chi Minh city, Vietnam. International Journal of physical Education, Sports and Health, 7(2), 65-68.

Thai, N. D., \& Son, V. T. (1999). Table tennis. Sports Publishing.

Toriola, A. L., Toriola, O. M., \& Igbokwe, N. U. (2004). Validity of Specific Motor Skills in Predicting Table-Tennis Performance in Novice Players. Perceptual and Motor Skills, 98(2), 584-586. https://doi.org/10.2466/pms.98.2.584-586

Welford, A. (1980). Choice reaction time: Basic concepts. Reaction times, 73-128. https://ci.nii.ac.jp/naid/10008956132/en/

Yuza, N., Sasaoka, K., Nishioka, N., Matsui, Y., Yamanaka, N., Ogimura, I., Takashima, N., \& Miyashita, M. (1992). Game analysis of table tennis in top Japanese players of different playing styles. International journal of table tennis sciences, 1, 79-89.

Zhang, P., Ward, P., Li, W., Sutherland, S., \& Goodway, J. (2012). Effects of Play Practice on Teaching Table Tennis Skills. Journal of Teaching in Physical Education, 31(1), 7185. https://doi.org/10.1123/itpe.31.1.71 
Tuan, Tran Minh; Dinh, Nguyen Mai

THE WORK-OUTS TO OPTIMIZE THE EFFICIENCY FOOTWORK - A CASE STUDY FOR TALENTED FEMALE TABLE TENNIS ATHLETES AT THE AGE OF 14-15 IN VINH LONG PROVINCE, VIETNAM

Creative Commons licensing terms

Authors will retain the copyright of their published articles agreeing that a Creative Commons Attribution 4.0 International License (CC BY 4.0) terms will be applied to their work. Under the terms of this license, no permission is required from the author(s) or publisher for members of the community to copy, distribute, transmit or adapt the article content, providing a proper, prominent and unambiguous attribution to the authors in a manner that makes clear that the materials are being reused under permission of a Creative Commons License. Views, opinions and conclusions expressed in this research article are views, opinions and conclusions of the author(s). Open Access Publishing Group and European Journal of Physical Education and Sport Science shall not be responsible or answerable for any loss, damage or liability caused in relation to/arising out of conflict of interests, copyright violations and inappropriate or inaccurate use of any kind content related or integrated on the research work. All the published works are meeting the Open Access Publishing requirements and can be freely accessed, shared, modified, distributed and used in educational, commercial and non-commercial purposes under a Creative Commons attribution 4.0 International License (CC BY 4.0). 